\title{
30 Years of Surfactant Research - From Basic Science to New Clinical Treatments for the Preterm Infant
}

The 30th International Workshop on Surfactant Replacement took place in Stockholm from June 5-6, 2015. This annual meeting has been held in different places all over Europe but now returns to the Karolinska Institutet where research by Bengt Robertson and Tore Curstedt on Curosurf $^{\circledR}$, a porcine surfactant, began in 1980 [1]. The meeting was held in the Aula Medica at Karolinska Institutet in the lecture hall where the Nobel Lectures in Physiology or Medicine are given.

The Workshop started with the 7th Bengt Robertson Memorial Lecture given by Eric Shinwell from Tsfat, Israel. His lecture was entitled 'The Risky Business of Prediction' in which he highlighted the difficulties in caring for infants born close to the limits of viability and the problems in predicting an individual infant's outcome and long-term future using population statistics - indeed a risky business [2].

As this was the 30th Anniversary of the first International Surfactant Workshop held in Amsterdam in 1986, Tore Curstedt from Stockholm described the history of the development of Curosurf and the first treatment of a preterm infant with this surfactant in the 1980s $[1,3]$. Henry Halliday from Belfast spoke about the first randomized controlled trial of Curosurf which began early in 1985 [4] and was the first to show that surfactant treatment could reduce neonatal mortality. He also reviewed the results of subsequent clinical trials of surfactant treatment performed during the last 30 years. The first clinical trial with a synthetic surfactant, composed of analogues of both hydrophobic surfactant proteins and phospholipids and developed in collaboration between the Karolinska Institutet and Chiesi Farmaceutici, was described by Christian Speer from Würzburg [1]. The presentation by Mats Blennow from Stockholm was about surfactant and noninvasive ventilation [5]. His conclusion was that there is mounting evidence that early continuous positive airway pressure from birth is feasible and safe even in very preterm infants and that a strategy for surfactant administration should be part of a noninvasive ventilation approach. This view is reflected in the latest European guidelines for the management of respiratory distress syndrome (RDS) [6].

Aaron Hamvas from Chicago discussed the benefits of high-throughput sequencing technology in order to identify the microbiota in various microenvironments of the human body $[7,8]$. He summarized data from elegant studies that suggested a microbial influence on the development of neonatal respiratory disease and he also highlighted many of the gaps that remain in understanding the function of the respiratory microbiome.

Bronchopulmonary dysplasia (BPD) was once described as primarily the result of postnatal injury from 
mechanical ventilation and oxygen therapy after preterm birth. Christopher Baker from Aurora, Colo. talked about the importance of antenatal and perinatal factors that interrupt lung development in infants born at the extremes of prematurity in the pathogenesis of BPD [9]. Perturbation of pulmonary vascular development may be more important than alveolar disruption. Simplified parenchymal architecture limits gas exchange and leads to increased cardiopulmonary morbidity and mortality. Advances in the understanding of pulmonary vascular development may lead to future therapies that may augment postnatal vascular growth to prevent and treat this severe chronic lung disease.

Steroid treatment was the topic of the talks given by Mikko Hallman from Oulu and Dirk Bassler from Zurich. Mikko Hallman discussed the effects of different corticosteroids on the fetus [10]. The fetal compartment is protected against endogenous corticosteroids by the enzymatic inactivation of cortisol, while fluorinated synthetic glucocorticoids effectively enter into the fetal compartment and are not inactivated. This knowledge is basic for successful antenatal glucocorticoid treatment for preventing serious consequences after preterm birth. Antenatal glucocorticoid aimed to be given within 1-10 days before preterm birth increases the success of postnatal treatments of very preterm infants.

Dirk Bassler addressed the very important and topical issue of inhaled steroid treatment to prevent BPD [11]. Systemic steroid therapy has in some studies been shown to reduce the incidence of BPD, but it has been linked to adverse neurodevelopmental outcomes in treated infants. Although a review from the Cochrane Collaboration concluded that there is no evidence to support the routine use of inhaled steroids for the prevention of BPD [12], the NEUROSIS study was conducted to test the theory that high-dose inhaled budesonide given early after birth to very preterm infants would prevent BPD [13]. Another way to deliver budesonide to the airways is by using surfactant as a vehicle [14]. This may also have a role in the prevention of BPD in extremely low birth weight infants, but further studies must be performed before its introduction to routine clinical care.

Bernard Thébaud from Ottawa discussed the therapeutic potential of stem cells in many diseases, including BPD [15]. Compelling preclinical data using stem cells show that these cells prevent/repair lung damage in animal models of experimental BPD. His review highlighted the exciting translation from bench to bedside that will hopefully lead in the near future to improved pulmonary outcomes in preterm infants.
Ola Saugstad from Oslo emphasized that delivery room management, especially in the first minute, is of utmost importance [16-18]. Antenatal care, selection of birth mode, thermal control, delayed cord clamping, and antenatal steroid therapy when indicated also contribute to securing the best outcome. He also pointed out that preterm infants in need of ventilatory support should start with continuous positive airway pressure from the first breath [5] and that surfactant instillation is often not needed prophylactically provided the mother has received antenatal steroids [6].

The Post-Conference Workshop comprised a number of interesting lectures. Hugo Lagercrantz from Stockholm gave a presentation on the onset of breathing and the emergence of the mind at birth, while Frank van Bel from Utrecht talked about the clinical relevance of neuromonitoring of high-risk preterm infants. Dominique Haumont from Brussels showed how Internet and information technology can be used to monitor nosocomial infections, while Kajsa Bohlin from Stockholm talked about family-centered care.

The Surfactant Workshop also comprised 16 short oral communications and 23 poster presentations. The review papers from the Workshop and the free oral communications are published in this issue of Neonatology. We would like to honor and remember Bengt Robertson who founded this series of workshops in 1986 and was the architect of our understanding of neonatal RDS and its treatment with surfactant [19]. Bengt Robertson was educated and active as a scientist at Karolinska Institutet and it is a great honor to celebrate his memory with the 30th Annual Workshop on Surfactant Replacement at Karolinska Institutet situated in his hometown of Stockholm.

Tore Curstedt, Stockholm
Henry L. Halliday, Belfast
Mikko Hallman, Oulu
Ola D. Saugstad, Oslo
Christian P. Speer, Würzburg

\section{Disclosure Statement}

The Scientific Committee is grateful to Chiesi Farmaceutici and its partners for financial support enabling this Workshop to take place. The scientific program was arranged by the Scientific Committee without interference from the sponsors. All members of the Scientific Committee are or have been consultants to Chiesi Farmaceutici. The content of the Workshop reflects the scientific opinions of the individual presenters and not the sponsor or its partners. 


\section{References}

$>1$ Curstedt T, Halliday HL, Speer CP: A unique story in neonatal research: the development of a porcine surfactant. Neonatology 2015; 107:321-329.

2 Shinwell ES: Ethics of birth at the limits of viability: the risky business of prediction. Neonatology 2015;107:317-320.

-3 Noack G, Berggren P, Curstedt T, Grossmann G, Herin P, Mortensson W, Nilsson R, Robertson B: Severe neonatal respiratory distress syndrome treated with the isolated phospholipid fraction of natural surfactant. Acta Paediatr Scand 1987;76:697-705.

4 Collaborative European Multicenter Study Group: Surfactant replacement therapy for severe neonatal respiratory distress syndrome: an international randomized clinical trial. Pediatrics 1988;82:683-691.

$>5$ Blennow M, Bohlin K: Surfactant and noninvasive ventilation. Neonatology 2015;107: 330-336.

6 Sweet DG, Carnielli V, Greisen G, Hallman M, Ozek E, Plavka R, et al: European consensus guidelines on the management of neonatal respiratory distress syndrome in preterm infants - 2013 update. Neonatology 2013;103: 353-368.
7 Warner BB, Hamvas A: Lungs, microbes and the developing neonate. Neonatology 2015; 107:337-343.

8 Sherman MP, Minnerly J, Curtiss W, Rangwala S, Kelley ST: Research on neonatal microbiomes: what neonatologists need to know. Neonatology 2014;105:14-24.

$\checkmark 9$ Baker C, Abman SH: Impaired pulmonary vascular development in bronchopulmonary dysplasia. Neonatology 2015;107:344-351.

10 Hallman M: The story of antenatal steroid therapy before preterm birth. Neonatology 2015;107:352-357.

11 Bassler D: Inhalation or instillation of steroids for the prevention of bronchopulmonary dysplasia. Neonatology 2015;107:358-359.

-12 Shah V, Ohlsson A, Halliday HL, Dunn MS: Early administration of inhaled corticosteroids for preventing chronic lung disease in ventilated very low birth weight preterm neonates. Cochrane Database Syst Rev 2007; 4:CD001969.
3 Bassler D, Halliday HL, Plavka R, Hallman M, Shinwell ES, Jarreau P-H, et al: The Neonatal European Study of Inhaled Steroids (NEUROSIS): an EU-funded international randomised controlled trial in preterm infants. Neonatology 2010;97:52-55

-14 Yeh TF, Lin HC, Chang CH, Wu TS, Su BH, Li TC, Pyati S, Tsai CH: Early intratracheal instillation of budesonide using surfactant as a vehicle to prevent chronic lung disease in preterm infants: a pilot study. Pediatrics 2008 ; 121:e1310-e1318.

15 O’Reilly M, Thébaud B: Stem cells for the prevention of neonatal lung disease. Neonatology $2015 ; 107: 360-364$.

16 Saugstad OD: Delivery room management of term and preterm newly born infants. Neonatology 2015; 107:365-371.

17 Saugstad OD: Oxygenation of the newborn: a molecular approach. Neonatology 2012;101: 315-325.

18 Vento M: Oxygen supplementation in the neonatal period: changing the paradigm. Neonatology 2014;105:323-331.

19 Halliday HL, Speer CP: Bengt Robertson (1935-2008): a pioneer and leader in surfactant research. Neonatology 2009;95:VI-VIII. 